\title{
A Review of Potential Antiviral Drugs and Vaccines to Treat COVID-19
}

\section{Sanjeet Singh ${ }^{1}$ (iD) and R. Jayaram* (D)}

University Centre for Research and Development, Chandigarh University, NH-95, Ludhiana - Chandigarh State Highway, Punjab - 140 413, India.

\begin{abstract}
Coronavirus disease 19 (COVID-19) is a challenge to the whole humanity. COVID-19 was first reported in China and rigorous researches are going on for developing vaccine for the pandemic. This review was prepared by following PRISMA guidelines and used the resources from the Web of Science and PubMed. This research focuses on the niches of symptoms and vaccines for COVID-19. The research for vaccine involves research for new vaccine and drug repurposing. Out of various drug repurposing options, Remdesivir, and Favipiravir, Chloroquine and Lopinavir/Ritonavir were found to be the popular ones for treating COVID-19 patients across the world. Even though there are concerns regarding asymptotic patients, the most dominant symptoms of COVID-19 are fever and cough, followed by Dyspnoea and muscle ache. This review concludes that the COVID-19 related research should focus on developing immunity vaccines, and repurposing of drugs. Research on the problems of quarantine life, patient monitoring, and usage of information technology in facing COVID-19 will improve the quality of patient handling during the pandemic. The research on the effectiveness of various models of lockdown and regulation of social life during lockdown periods, improving the safety of health care workers in the workplace will definitely help the governments in their fight against COVID-19.
\end{abstract}

Keywords: COVID-19, Coronavirus, Vaccine, Pandemic, SARS-CoV-2

\footnotetext{
*Correspondence: jayaram.fin@gmail.com; +91 9872354909
}

(Received: April 29, 2020; accepted: May 20, 2020)

Citation: Singh S, Jayaram R. A Review of Potential Antiviral Drugs and Vaccines to Treat COVID-19. J Pure Appl Microbiol. 2020;14(suppl 1):765-774. doi: 10.22207/JPAM.14.SPL1.14

(C) The Author(s) 2020. Open Access. This article is distributed under the terms of the Creative Commons Attribution 4.0 International License which permits unrestricted use, sharing, distribution, and reproduction in any medium, provided you give appropriate credit to the original author(s) and the source, provide a link to the Creative Commons license, and indicate if changes were made. 


\section{INTRODUCTION}

Coronavirus disease19 (COVID-19), was first reported at Huanan Seafood Wholesale Market, Wuhan city, Hubei province in China in December 2019 as pneumonia with an unknown cause. The name "COVID-19" was officially assigned to the pandemic by the World Health Organization (WHO). This new type of coronavirus was isolated on $7^{\text {th }}$ January 2020 and the genetic sequence of the novel coronavirus was shared on $12^{\text {th }}$ January by China, which had thrown some light to the new unknown enemy to the world (WHO Situation Report 2020). The virus that is spreading COVID 19 had been identified as a member of the coronavirus family and named Severe Acute Respiratory Syndrome Coronavirus 2 (SARS-CoV-2) by International Committee on Taxonomy of Viruses (ICTV) ${ }^{1-5}$. However, there are also reports that the novel coronavirus had been named by Chinese authorities ${ }^{6}$. The word "Corona" is a Latin word which means "crown" and (SARS-CoV-2) resembles a crown in its appearance when observed under an electron microscope. SARS-CoV-2 is a single-stranded RNA virus of the order "Nidovirales", of Coronaviridae family, a beta genera coronavirus ${ }^{5,7,8}$. SARS-CoV-2 is the seventh coronavirus and the other human coronaviruses (HCoV) such as HCoV-NL63, HCoV-
229E, HCoV-OC43, and HKU1 typically cause mild upper respiratory tract infections in the healthy pupil and can be dangerous in older adults ${ }^{3,8}$. 2019-nCoV, which has a $75-80 \%$ similarity with Severe Acute Respiratory Syndrome Coronavirus (SARS-CoV) and $50 \%$ similarity with the Middle East Respiratory Syndrome Coronavirus (MERS(oV) $)^{5,9,10} ; 70 \%$ similarity with Severe Acute Respiratory Syndrome Coronavirus (SARS-CoV-2) was reported ${ }^{11}$; $45 \%-90 \%$ similarity with Severe Acute Respiratory Syndrome Coronavirus (SARSCoV-2) was reported ${ }^{1}$ and $20 \%-60 \%$ similarity with the Middle East Respiratory Syndrome Coronavirus (MERS-CoV). A full genome evolutionary analysis had found that SARS-CoV-2 has $96 \%$ and more similarity with bat coronavirus ${ }^{9,11,12}$. Bats can be the potential hosts for SARS-CoV-2 ${ }^{1,9}$. The mechanism of viral entry and replication and RNA packing in the human cell is mapped ${ }^{13}$ and presented in Fig. $1^{13}$.

The virus had spelled its disastrous effect internationally, Thailand was the first country to report the first COVID-19 case outside the mainland of China ${ }^{14}$ (WHO Situation Report). WHO had declared Public Health Emergency of International Concern on $30^{\text {th }}$ January 2020 15. SARS-CoV-2 replicates rapidly in the upper respiratory tract or lower respiratory tract and
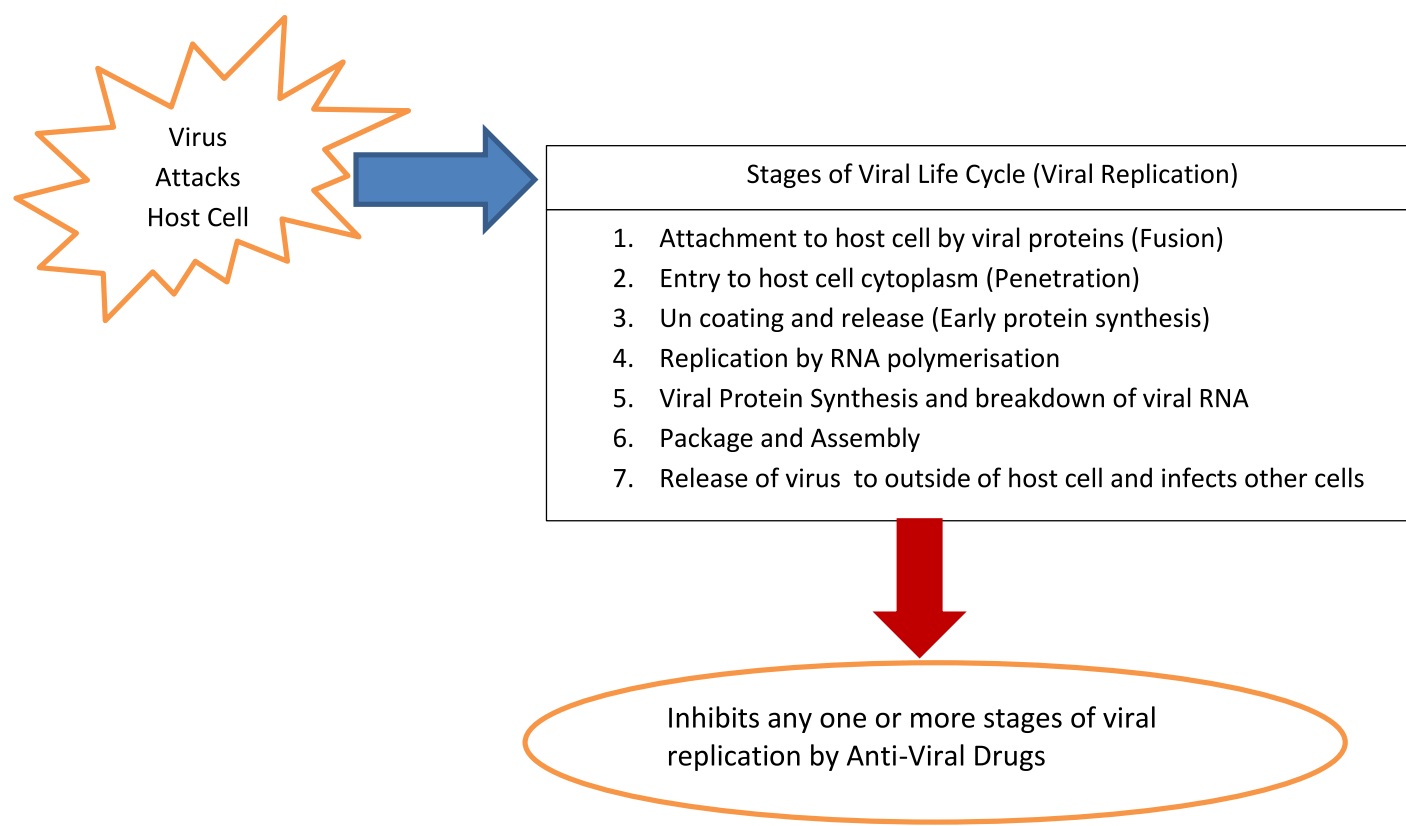

Fig. 1. Mechanism of Action of Anti-Viral Drugs 
may be transmitted to others, even from an asymptotic patient. Moreover, the risk is high due to asymptotic and mildly infected patients. It's urgent to identify and isolate the asymptotic to check the COVID-19 outbreak $^{16}$. This feature makes it challenging to control the outbreak of COVID-19, ${ }^{5,16,17}$.

COVID-19 resulted in much less mortality rate $^{1},(6 \%$ as on $09 / 04 / 2020)$ compared to SARS (9.6\%) and MERS (34.4\%). However, the mortality rate of SARS, MERS, and H1N1 was reported as $10 \%, 40 \%$, and $0.26 \%$ respectively ${ }^{19}$. The morbidity of COVID-19 is comparatively low and dependent upon, temperature, population density, and susceptibility of disease in the population. It had been observed that lack of detection and lack of awareness leads to less confirmed cases in the initial stages and thereby increases the uncertainty. COVID is being affected like seasonal influenza, a mild disease for most of the individuals, but may have a severe effect on older people and those with comorbidities ${ }^{17,18}$. However the fatality risk of COVID-19 has to be addressed only after considering the factors of obstacles, unreported death cases due to COVID-19, delay in the time of illness to death. The threat of non-reporting of mildly affected cases and asymptomatic cases; the problems associated with shorted virus detection windows and less sensitive diagnostic laboratory tests must be considered while calculating the fatality risk ${ }^{18}$. Similarly, the increased availability of testing kits and clinical resources may result in higher confirmed cases than the actual ${ }^{11}$.

Nucleic Acid Testing (NAT) is widely used for patient diagnosis and treating COVID-19 ${ }^{21}$. The SARS-CoV- 2 and can be killed at $56^{\circ} \mathrm{C}$ for 30 minutes. Similarly, ether, $75 \%$ ethanol, chlorine disinfectant, peracetic acid, and chloroform can effectively inactivate the SARS-CoV- $2^{1}$. Surface disinfectants with $62-71 \%$ ethanol, $0.5 \%$ hydrogen peroxide or $0.1 \%$ sodium hypochlorite can inactivate the SARS-CoV- $2{ }^{5}$. There are proofs that thermal inactivation adversely affected the COVID-19 detection tests and ultimately resulted in false-negative results ${ }^{21}$.

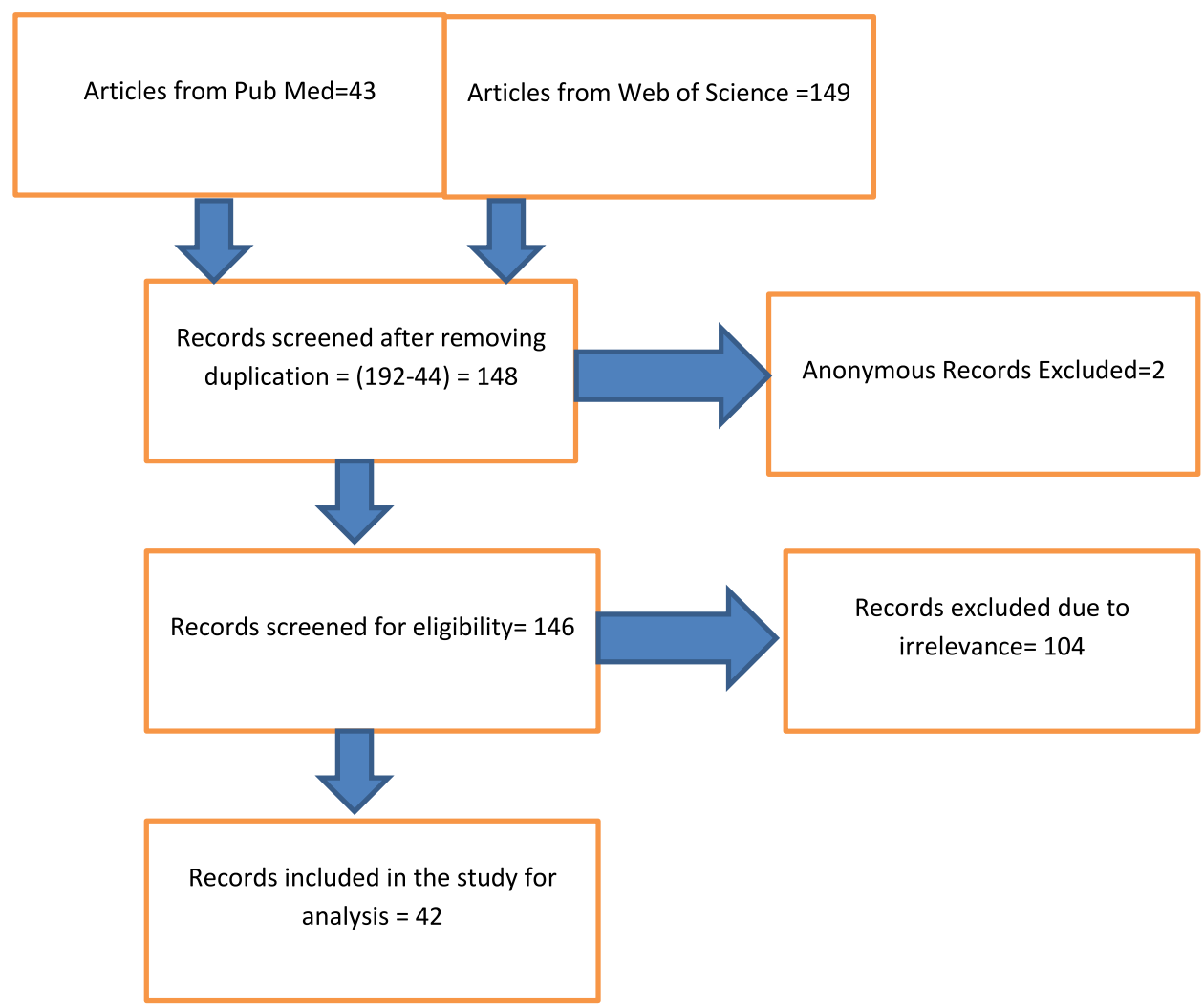

Fig. 2. Journal selection by PRISMA guideling 
There is a difference between the incubation period and the quarantine period. The period from the date of infection to date of illness onset is called the incubation period and the quarantine period is the period of monitoring and travel control of individuals. The incubation period had been found as (2-14days) with a $95 \%$ confidence level and the suggested quarantine period for COVID patients was at least 14 days ${ }^{20}$.

\section{METHODOLOGY}

This paper is divided into four sections. The first section is the introduction. The second section deals with methodology, by which literature was reviewed, and the third section deals with the discussion on literature, and the fourth section deals with findings, and conclusion. The articles for review had been selected according to PRISMA guidelines of 2009 and the details had been shown in (Fig. 2).

Review Objective

To consolidate the literature related to COVID-19.

To identify research gaps related to treatment and control of COVID-19

The following research questions had been framed for a systematic selection of articles for this review.

Research Question

What are the symptoms of COVID-19?

What are the possible vaccines for COVID-19?

How can we contain the super spreading of COVID-19?

Selection of Journals and Proceedings by PRISMA Guidelines

\section{DISCUSSION}

Transmission and transmission control measures

World Health Organization had implemented public health measures of rapid identification, diagnosis, and management of the cases, identification, and follow-up of contacts, infection prevention and control in health care settings, implementation of health measures for travelers, awareness-raising in the population, and risk communication to control the COVID-19.

The high correlation of case detection with airborne movement points out the risk of transmission of the COVID-19 across the globe ${ }^{22,23}$. The potential risk of international spread age from four Chinese cities of Wuhan, Beijing, Shanghai, and Guangzhou was studied using airline destination data (1$30^{\text {th }}$ January 2020) and ranked the destination countries according to the risk of corona spread age. The suggested measures to check this concern are early case recognition, isolation of identified case, treatment ${ }^{22,24}$; contact tracing, closure of certain routes, risk communication, targeted airport screening, public awareness, and vigilance of health workers ${ }^{22}$. The major challenges for the super spreading of COVID-19 are commercial air travel, poor local health protection systems, local contextual variables of hygiene practices, crowding and infection control practices, poor infectious disease surveillance systems. The risk and burden COVID-19 would be high on countries following a private health care system and on economies having poor and limited health infrastructure ${ }^{23}$.

There are multiple variables to be considered to prevent massive outbreaks of COVID-19 outside china a) Connectivity to china b) cumulative cases in the mainland of China, outside closed areas, c) efficiency of travel restrictions d) efficiency of entry screening at destination e) Efficiency of control measures in destination countries f) Local reproduction number (Rloc). Moreover, countries with low connectivity with China and high (Rloc) should focus on lowering import cases by entry screening or travel restrictions. Countries with high connectivity but low (Rloc) should focus on measures for reducing $(\text { Rloc })^{14}$.

Travel restrictions have been identified as a popular model for checking the rapid spreading of the novel coronavirus, COVID-19. Studies had found that the historic lockdown (Vehicles, train, and flights) (Wuhan on $23^{\text {rd }}$ January 2020; Wenzhou and Shenzhen on $12^{\text {th }}$ February 2020) had reduced the travel volume in Mainlands of China and prevented the risk of corona export, and reduced the probability of a major epidemic in Japan. This study had considered the shortcomings of travel restrictions; the difference between complete lockdown of country and lockdown of few cities; Issues related to missing patients with mild symptoms, while in screening procedure ${ }^{25}$.

There are serious concerns regarding asymptomatic travelers (incubating travelers and travelers concealing fever) in screening centers 
Table 1. Symptoms of COVID-19

\begin{tabular}{|c|c|c|c|c|c|c|c|c|c|c|}
\hline References > & $\begin{array}{l}\text { (Deng } \\
\text { and } \\
\text { Peng, } \\
2020)^{1}\end{array}$ & $\begin{array}{c}\text { (X.-W. } \\
\text { Xu e } \\
\text { t al., } \\
2020)^{10}\end{array}$ & $\begin{array}{c}\text { (Wax } \\
\text { and } \\
\text { Christian, } \\
2020)^{19}\end{array}$ & $\begin{array}{l}\text { (Deng } \\
\text { and } \\
\text { Peng, } \\
2020)^{1}\end{array}$ & $\begin{array}{l}\text { (X. Xu } \\
\text { et al., } \\
2020)^{8}\end{array}$ & $\begin{array}{l}\text { (Spiteri } \\
\text { et al., } \\
2020)^{42}\end{array}$ & $\begin{array}{l}\text { (Deng } \\
\text { and } \\
\text { Peng, } \\
2020)^{1}\end{array}$ & $\begin{array}{c}\text { (Su } \\
\text { et al., } \\
2020)^{2}\end{array}$ & $\begin{array}{c}\text { (Lai } \\
\text { et al., } \\
2020)^{5}\end{array}$ & $\begin{array}{c}\text { Total } \\
\text { and \% }\end{array}$ \\
\hline No of cases & 41 & 62 & 99 & 99 & 90 & 29 & 41 & 14 & 278 & 753 \\
\hline Fever & $80.50 \%$ & $77 \%$ & $83 \%$ & $83 \%$ & $78 \%$ & $72.41 \%$ & $98 \%$ & $57.10 \%$ & $92.80 \%$ & $85.30 \%$ \\
\hline Cough & $56.10 \%$ & $81 \%$ & - & $82 \%$ & $63 \%$ & $48.27 \%$ & $76 \%$ & $35.70 \%$ & $69.80 \%$ & $60.46 \%$ \\
\hline Pneumonia & - & & - & $75 \%$ & - & - & $100 \%$ & - & - & $15.30 \%$ \\
\hline Short of Breath & $31.70 \%$ & $3 \%$ & $17 \%$ & $31 \%$ & - & $6.89 \%$ & - & - & - & $8.54 \%$ \\
\hline Chest pain & $24.40 \%$ & - & - & $2 \%$ & - & - & - & $21.40 \%$ & - & $0.19 \%$ \\
\hline Fatigue & $22 \%$ & $52 \%$ & - & - & $19 \%$ & - & $44 \%$ & $21.40 \%$ & - & $0.11 \%$ \\
\hline Dyspnoea & $12.20 \%$ & - & - & - & - & - & $55 \%$ & - & $34.50 \%$ & $16.41 \%$ \\
\hline Diarrhoea & - & $8 \%$ & - & $2 \%$ & $6 \%$ & $3.45 \%$ & $3 \%$ & - & $6.10 \%$ & $4.50 \%$ \\
\hline Headache & $4.90 \%$ & $34 \%$ & - & $8 \%$ & $4 \%$ & $20.69 \%$ & $8 \%$ & - & $7.20 \%$ & $8.48 \%$ \\
\hline Confusion & - & - & - & $9 \%$ & - & - & - & - & - & $1.18 \%$ \\
\hline General pain & $7.30 \%$ & - & - & - & - & - & - & - & - & $0.40 \%$ \\
\hline Sore Throat & - & - & - & $5 \%$ & $26 \%$ & $6.89 \%$ & - & $7.10 \%$ & $5.10 \%$ & $6.05 \%$ \\
\hline Chill & $4.90 \%$ & - & - & - & $7 \%$ & - & - & - & - & $1.10 \%$ \\
\hline Muscle ache & - & - & - & $11 \%$ & $25 \%$ & $3.45 \%$ & - & - & $27.70 \%$ & $14.70 \%$ \\
\hline Rhinorrhoea & - & - & - & $4 \%$ & - & $6.89 \%$ & - & - & $4 \%$ & $0.02 \%$ \\
\hline $\begin{array}{l}\text { Nausea and } \\
\text { vomiting }\end{array}$ & - & - & - & $1 \%$ & $6 \%$ & $3.45 \%$ & - & - & - & $0.98 \%$ \\
\hline Lymphopenia & - & - & - & - & - & - & $63 \%$ & - & - & $3.43 \%$ \\
\hline Sputum production & - & - & - & - & $12 \%$ & - & $28 \%$ & - & - & $2.95 \%$ \\
\hline Haemoptysis & - & $3 \%$ & - & - & - & - & $5 \%$ & - & - & $0.51 \%$ \\
\hline Pharyngalgia & - & - & - & - & - & - & - & - & $17.40 \%$ & $6.42 \%$ \\
\hline Weakness & - & - & - & - & - & $27.58 \%$ & - & - & - & $1.06 \%$ \\
\hline Expectoration & - & $56 \%$ & - & - & - & - & - & - & - & $4.61 \%$ \\
\hline
\end{tabular}

(temperature/fever screening), who are missing out on the surveillance. This situation can be better tackled and concerns of imported cases can be reduced by imposing travel restrictions to and from high-risk areas and/or a mandatory quarantine for travelers from high risk ${ }^{26}$. Timely diagnosis cannot avoid the spreading of COVID-19 but can reduce the transmission of the epidemic and thereby the mounting cases and total infection. However, more rigorous measures like increasing available hospital beds, shortening the period from symptoms to isolation, quarantining, and isolation of both suspected and infected cases are recommended for reducing the spread age of COVID-1927.

There are multiple hotspots for the spread of COVID-19 and the relevance of focusing only on Chinese connection had been reduced significantly. The effectiveness of travelers' screening was studied and estimated that the traveler screening method may miss more than half of the infected people. The factors responsible missing in screen test are due to asymptotic travelers who are either unaware that they are exposed, symptoms had not been developed at the stage of the screening test, variation in severity and detectability, the poor performance of screening equipment or personnel; or active evasion of screening by travelers. These point outs the need for measures to check the transmission from asymptotic travelers ${ }^{28}$. Asymptotic infections are a serious challenge in defending COVID-19 due to the transmission potential of virus carriers (Up to 3 weeks) and may cause serious illness to the communicated persons. The recommended measures against these challenges can be close contact tracing and longitudinally surveillance via virus nucleic acid tests ${ }^{16,21}$.

Quarantine was found to be successful in controlling COVID-19 in Wuhan and its efficiency was tested by using the SEIR model (Suspected, Exposed, Infectious, and Recovered) and found that, reducing the contact rate of latent individuals 
after quarantine and isolation can effectively reduce the number of individuals infected with COVID-19 and delay the peak time ${ }^{4}$.Quarantining and isolation may create unbearable psychological pressure and mental problems. Novel intervention strategies that are feasible and accessible is to be designed to address this issue. Structured letter therapy (remote written counseling) can be used along with conventional face to face psychological counseling for improving the mental health of the patients ${ }^{29}$.

Prevention, control, diagnosis, and treatment are the pillars in defending COVID-19. A judicious combination of the above measures is required strategically defending a pandemic like COVID-19. The most useful strategies used in China to defend COVID-19 are detecting cases early, isolate every patient, trace every contact, provide quality clinical care, prevent hospital outbreaks, prevent community transmission, avoid public panic and rumor, progress vaccines and therapeutic ${ }^{27}$.

There are pieces of evidence for nosocomial transmission of the COVID-19 among humans and strict precautionary measures have to be taken among other patients, visitors, and other health care workers ${ }^{1,9,19,30}$.

Pregnant women too are not immune to COVID-19, but the impact of COVID-19 on pregnant women is comparatively less severe than the impact caused by SARS, H1N1, and MERS. And there is less possibility of infection transmission to babies through breastfeeding ${ }^{31}$. However some studies found that pregnant women may be at high risk during the Corona outbreak, but it is still unclear that whether COVID-19 increases the risk of miscarriage, stillbirth, preterm delivery, fetal tachycardia, and fetal distress. There is no recorded evidence regarding the risk of transmission of infection from mother to fetus but there is a possibility of infection transmission to babies through breastfeeding ${ }^{32}$.

Precautionary measures for health care workers COVID-19 was found to be spreading by a human to human transmission through, direct contact and droplets ${ }^{5,19,33}$. This is a major concern for all especially health workers and the common men. Health care workers had reported their anxiety, stress, and fear during COVID outbreaks, and the recommended precautionary measures

Table 2. Drugs repurposed for treating COVID-19

\begin{tabular}{|c|c|}
\hline Repurpose of antiviral agents & Citations \\
\hline Arbidol & $(\text { Dong, Hu and Gao, 2020) })^{38}\left(\right.$ X.-W. Xu et al., 2020) ${ }^{10}($ Cao, Tu, et al., 2020) \\
\hline $\begin{array}{l}\text { Pegylated interferon alfa- } \\
2 a \text { and }-2 b\end{array}$ & (Li and De Clercq, 2020) ${ }^{35}$ \\
\hline Remdesivir, and Favipiravir & $\begin{array}{l}\text { (Dong, Hu and Gao, 2020) })^{38}(\text { Li and De Clercq, 2020) })^{35} \\
(\text { MacKenzie, 2020) })^{39}\left(\text { Lai et al., 2020) }{ }^{5} \text { (Negahdaripour, 2020) }\right. \\
\left(\text { Martinez, 2020) }{ }^{40}(\text { Arabi, Murthy and Webb, 2020) }\right.\end{array}$ \\
\hline Galidesivir & (Li and De Clercq, 2020) 35 \\
\hline Ribavirin & $\begin{array}{l}\text { (Li and De Clercq, 2020) } \\
\text { Hu and Gao, 2020) }{ }^{38}\end{array}$ \\
\hline Lopinavir/Ritonavir & $\begin{array}{l}\left.(\text { Lai et al., 2020) })^{5} \text { Lim et al., 2020 }\right)^{41}(\text { Arabi, Murthy and Webb, 2020) })^{9} \\
(\text { Cheng and Shan, 2020) })^{11}\left(\text { Deng and Peng, 2020) }{ }^{1} \text { (Negahdaripour, 2020) }\right. \\
(\text { X.-W. Xu et al., 2020) })^{10}(\text { Cao, Tu, et al., 2020) })^{36}(\text { Martinez, 2020 })^{40} \\
(\text { Dong, Hu and Gao, 2020) })^{38}\end{array}$ \\
\hline Chloroquine, & $\begin{array}{l}\left.\text { (Dong, Hu and Gao, 2020) })^{38} \text { (Li and De Clercq, 2020) }\right)^{35} \text { (Lai et al., 2020) } \\
\text { (MacKenzie, 2020) }^{39} \text { (Negahdaripour, 2020) }^{7} \text { (Arabi, Murthy and Webb, } \\
2020)^{9}(\text { Cao, Tu, et al., 2020) }\end{array}$ \\
\hline Oseltamivir, ganciclovir & $\left(\text { Cheng and Shan, 2020) }{ }^{11} \text { (Cao, Tu, et al., 2020) }\right)^{36}$ (Lai et al., 2020) \\
\hline Kaletra & $\left(\text { MacKenzie, 2020) }{ }^{39} \text { (Lai et al., 2020) }{ }^{5} \text { (Cheng and Shan, 2020) }\right)^{11}$ \\
\hline Favilavir, & (Negahdaripour, 2020) ${ }^{7}$ \\
\hline $\begin{array}{l}\text { Cephalosporins, Quinolones, } \\
\text { Carbapenems, Linezolid, } \\
\text { Immunoglobulin, Thymosin }\end{array}$ & (Cao, Tu, et al., 2020)36 \\
\hline Alpha for Injection & \\
\hline
\end{tabular}

Journal of Pure and Applied Microbiology 
in hospitals are contact and droplet precautions, environmental disinfection, and airborne precautions. The local precautionary measures are also to be followed ${ }^{9}$. Health care workers should be vigilant while dealing with bag-valvemask ventilation, non-invasive ventilation, and intubation, which can allow airborne transmission to those closely involved in the procedure. The recommended PPE for COVID-19 includes gloves, eye protection, fluid-resistant gown, full face shield, hair covers or hoods, and N95 mask or PAPRs (Powered Air Purifying Respirators), hand sanitization $^{19}$. The fight against COVID-19 is so hard and an observational study using structural equation modeling had identified that the medical staff engaged in treating COVID-19 patients in China had levels of anxiety, stress, and self-efficacy, which were affected due to the sleep quality ${ }^{34}$. Symptoms

There are no distinguished symptoms for COVID-19, and most of the symptoms are overlapped with SARS and $\mathrm{MERS}^{9}$. As the symptoms of COVID-19 are similar to other respiratory diseases (Fever-83\%-98\%, cough76\%-82\% and short of breath $31 \%-55 \%$ ), differential analysis and better screening are required for travelers arriving from foreign countries, for better defending of spreading of the virus ${ }^{6}$. Various studies had been conducted across the world regarding the symptoms of COVID-19. Table 1 describes the major symptoms of the disease.

Researches for vaccine and antiviral:

Potential Vaccines

Some companies such as CureVac and Tonix Pharmaceuticals; GeoVax and BravoVax; Takis and Evvivax; iBio and CC-Pharming; Regeneron Pharmaceuticals; GSK had started their research for creating a vaccine for COVID-19. Similarly, The University of Queensland had also started its initiatives to develop a vaccine for COVID-197.

Vaccine for COVID-19 is one of the hot topics for research and an immunoinformatic approach based study by using molecular dynamics simulations had identified five CTL epitopes, three sequential $B$ cell epitopes and five discontinuous B cell epitopes in the viral surface glycoprotein, $76.3 \%$ identical and $87.3 \%$ similar with spike glycoprotein of SARS-COV. Moreover, the simulations had observed the CTL epitopes to be binding $\mathrm{MHC}$ class I peptide-binding grooves via multiple contacts, with continuous hydrogen bonds and salt bridge anchors. This observation manifolds their potential in generating immune responses and the research concludes that some of these epitomes can be the potential candidates for the development of a vaccine for COVID-19 ${ }^{37}$. Usage of antiviral agents

There is no specific antiviral treatments of vaccines are available yet $t^{1,5,14,17,24,25,33,35}$ and as it would take months and years to develop new interventions for COVID-19, the current focus is on the potential to repurpose existing antiviral agents can be used as potential candidates against COVID-19 ${ }^{35,36}$ or controlling transmission through travel control measures.

Arbidol, the antiviral, (200mg/day) 10,38 is popularly used to treat influenza can effectively inhibit SARS-CoV-2 ${ }^{30}$. Similarly, clinical trials are undergoing for the usage of Pegylated interferon alfa-2a and -2b, used for HBV and HVC for COVID patients. But interferons are associated with multiple adverse effects and need stringent monitoring and usage $\mathrm{e}^{35}$. Favipiravir can effectively inhibit RNA viruses such as influenza, Ebola, yellow fever, chikungunya, norovirus, and enterovirus. Favipiravir has been undergoing clinical trials to use against COVID-19 ${ }^{1,35}$. Favipiravir has been believed to have more antiviral action and a negligible adverse effect than lopinavir/ ritonavir ${ }^{38}$. Remdesivir is an antiviral drug, an RNA polymerase inhibitor, first developed for Ebola is also undergoing large trials for defending COVID-19 5,7,9,39. Remdesivir was found successful in inhibiting virus replication in the case of SARS and MERS in tissue cultures 40 . Ribavirin used for treating COVID- $19^{9}$ approved for treating HCV and Respiratory syncytial virus (RSV), but the high dosage may lead to Anaemia ${ }^{35}$. Ribavirin should be administered via intravenous infusion at a dose of $500 \mathrm{mg}$ for adults, 2 to 3 times/ day ${ }^{38}$. Kaletra, a combination of two anti-HIV drugs, which stops replication of virus had been used in China, against COVID-195,39. The efficiency of Galidesivir developed for HCV, which had shown antiviral activities RNA viruses including SARS and MERS should also be evaluated as a potential drug against COVID-19 ${ }^{35}$. Lopinavir/ Ritonavir had been found successful in controlling SARS in patients and tissue culture ${ }^{5,7,9,30,40} .2$ tablets of $200 \mathrm{mg} / 40-50 \mathrm{mg}$ can reduce beta 
coronavirus loads significantly, subjected to more clinical trials $\mathrm{s}^{1,38,41} 400 \mathrm{mg} / 200 \mathrm{mg}$ twice daily $10500 \mathrm{mg}$ twice daily 11 . Chloroquine can successfully inhibit SARS COV2 $2^{5,7,30,35}$. Chloroquine Phosphate, an antimalarial drug, 500mg (300mg Chloroquine), 2 times a day was suggested against COVID-1938,39. Favilavir is an approved drug in China for the treatment of COVID-197. Oseltamivir (75 mg every $12 \mathrm{~h}$, orally), ganciclovir (0.25 g every $12 \mathrm{~h}$, intravenously) were used in China ${ }^{5,11}$. Cephalosporins, Quinolones, Carbapenems, Linezolid, Immunoglobulin, Thymosin Alpha for Injection were also used limitedly for defending COVID-1930.

\section{CONCLUSION}

The first level of global spreading started from the Chinese city of Wuhan and the travel restrictions and screening was the first step adopted by Countries to stop imported cases. However, due to the massive outbreak of COVID-19 across the globe, there are multiple hotspots now in the world, other than Wuhan in China. The other strategic steps are contact tracing, closure of certain routes, risk communication, targeted airport screening, public awareness and vigilance of health workers, hygiene practices, infection control practices, activation of disease surveillance systems, quarantining, and isolation of both suspected and infected cases. Even though quarantining and isolation is the best solution to slow down the spread of the disease, it results in psychological pressure and affects the mental health of COVID-19 patients. Proper counseling can be a solution to address such issues. There are concerns regarding the efficiency of travelers screening due to the presence of asymptotic travelers and mild patients.

By analyzing the symptoms of COVID patients ( 753 patients) in nine different studies, we had sorted out the major symptoms of COVID-19. Fever and Cough are the most dominant symptoms of COVID-19. The symptom of fever was present in $85.3 \%$ of the patients, followed by cough $60.46 \%$, Dyspnoea $16.41 \%$, Pneumonia 15.3\%. General pain, chest pain, Fatigue, and Rhinorrhoea are the feeble symptoms of COVID-19. None of these symptoms should be taken casually, as there are chances of these symptoms in mild cases.
There are serious concerns regarding asymptotic patients who can be carriers of SARS COV2. Managing of asymptotic patients is very crucial as any minor case of negligence can lead to the outbreak of the pandemic.

Many of the Pharmaceutical companies across the world are busy in their research for finding a medical solution for the threat of SARS COV2. There are a few studies for developing a new vaccine, but the majority of the researches are focusing on drug repurposing by using various drugs used for other diseases like Ebola, Malaria, SARS, MERS, HIV, etc for treating COVID-19 patients.

Arbidol and Pegylated interferon had undergone several clinical trials and used for the treatment of COVID-19. However stringent monitoring and usage are recommended for the usage of later due to its adverse effects. Favipiravir, lopinavir/ritonavir, and Remdesivir are common antiviral drugs repurposed for the treatment of COVID-19. Favipiravir has more antiviral effectiveness and less adverse effects than lopinavir/ritonavir. Remdesivir is an antiviral drug used for inhibiting virus replication. Ribavirin is also used for the treatment of COVID-19 but having the adverse effect that high dosage may lead to Anaemia. Lopinavir/Ritonavir, Kaletra, and Galidesivir are also used for stopping viral replication. Chloroquine had been used in many countries to defend COVID-19. The other repurpose drugs used for treating COVID-19 patients are Favilavir, Oseltamivir, ganciclovir, Cephalosporins, Quinolones, Carbapenems, Linezolid, Immunoglobulin, and Thymosin Alpha for Injection.

Futuristic research can be on developing new medicines, immunity vaccines, repurposing of drugs. Many of clinically trialed drugs also require rigorous population studies to prove their reliability. Research can be a focus on the issue of problems of quarantine life, monitoring, usage of information technology in facing COVID-19. Futuristic researches can be for better systems of travel control during the lockdown, evaluation of the effectiveness of various models of lockdown, monitoring and regulation of social life during lockdown periods, improving the safety of health care workers in the workplace and better dealing 
of asymptotic patients. The economic aspects of lockdown will be of great importance once the epidemic is settled.

\section{ACKNOWLEDGMENTS}

All listed author(s) are thankful to their representative universities/institutes for providing the related support to compile this work.

\section{CONFLICT OF INTEREST}

The authors declares that there is no conflict of interest.

\section{AUTHORS' CONTRIBUTION}

All authors have made a substantial and intellectual contribution to the work, and approved it for publication.

\section{FUNDING}

None.

\section{ETHICS STATEMENT}

This article does not contain any studies with human participants or animals performed by any of the authors.

\section{DATA AVAILABILITY}

All datasets generated or analyzed during this study are included in the manuscript and/or the Supplementary Files

\section{REFERENCES}

1. Deng S-Q, Peng H-J. 'Characteristics of and public health responses to the coronavirus disease 2019 outbreak in China', J Clinical Med. 2020;9(2). https://doi.org/10.3390/ jcm9020575

2. Su L. et al. 'The different clinical characteristics of coronavirus disease cases between children and their families in China - the character of children with COVID-19.', Emerging Microbes \& Infections, 2020;9(1):707-713. https://doi.org/10.1080/22221751 .2020 .1744483

3. Lum LHW, Tambyah PA. 'Outbreak of COVID-19-an urgent need for good science to silence our fears?', Singapore Medic J, 2020;61(2):55-57. doi: 10.11622/smedj.2020018. https://doi.org/10.11622/smedj.2020018

4. Hou C, et al. 'The effectiveness of the quarantine of Wuhan city against the coronavirus disease 2019 (COVID-19): well-mixed SEIR model analysis.', J Medical Virol. 2020; The United States. https://doi.org/10.1002/ jmv. 25827

5. Lai C-C et al. 'Severe acute respiratory syndrome coronavirus 2 (SARS-CoV-2) and coronavirus disease-2019 (COVID-19): The epidemic and the challenges', Int J
Antimicrob Agents. 2020;55(3). https://doi.org/10.1016/j. ijantimicag.2020.105924

6. Bordi L et al. 'Differential diagnosis of illness in patients under investigation for the novel coronavirus (SARS-CoV-2), Italy, February 2020', Eurosurveillance. 2020;25(8):2-5. https://doi.org/10.2807/1560-7917. ES.2020.25.8.2000170

7. Negahdaripour M. 'The Battle Against COVID-19: Where Do We Stand Now?', Iranian Journal Of Medical Sciences. 2020;45(2):81-82. doi: 10.30476/ijms.2020.46357.

8. $\mathrm{XuX}$ et al. 'Imaging and clinical features of patients with 2019 novel coronavirus SARS-CoV-2', European Journal Of Nuclear Medicine and Molecular Imaging. 2020; 1-6. https://doi.org/10.1007/s00259-020-04735-9

9. Arabi YM, Murthy S, Webb S. 'COVID-19: A novel coronavirus and a novel challenge for critical care', Intensive Care Medicine. 2020;1-4.https://doi. org/10.1007/s00134-020-05955-1

10. $\mathrm{Xu} \mathrm{X-W}$ et al. 'Clinical findings in a group of patients infected with the 2019 novel coronavirus (SARS-Cov-2) outside of Wuhan, China: retrospective case series', BMJ. 2020;368. https://doi.org/10.1136/bmj.m606

11. Cheng ZJ, Shan J. '2019 Novel coronavirus: where we are and what we know', Infection. 2020;48:155-163. doi: 10.1007/s15010-020-01401-y. https://doi.org/10.1007/ s15010-020-01401-y

12. Paraskevis D et al. 'Full-genome evolutionary analysis of the novel coronavirus (2019-nCoV) rejects the hypothesis of emergence as a result of a recent recombination event', Infect Genet Evol. 2020;79. doi: 10.1016/j. meegid.2020.104212. https://doi.org/10.1016/j. meegid.2020.104212

13. Subramanian Boopathi, Adolfo B. Poma,Ponmalai Kolandaivel 'Novel 2019 coronavirus structure, mechanism of action, antiviral drug promises and rule out against its treatment', J Biomol Struct Dyn. 2020. https://doi.org/10.1080/07391102.2020.1758788

14. Boldog $\mathrm{P}$, et al. 'Risk assessment of novel coronavirus COVID-19 outbreaks outside China', Journal of Clinical Medicine. 2020;9(2). https://doi.org/10.3390/ jcm9020571

15. Barry M, Al Amri M, Memish ZA. 'COVID-19 in the shadows of MERS-CoV in the Kingdom of Saudi Arabia', J Epidemiol Global Health. 2020;10(1):1-3. https://doi. org/10.2991/jegh.k.200218.003

16. Hu Zhiliang, et al. 'Clinical characteristics of 24 asymptomatic infections with COVID-19 screened among close contacts in Nanjing, China', Science China-Life Sciences. 2020. https://doi.org/10.1007/s11427-0201661-4

17. Heymann DL, et al. 'COVID-19: what is next for public health?', Lancet. 2020;395(10224):542-545. doi: 10.1016/S0140-6736(20)30374-3.

18. Kobayashi T, et al. 'Communicating the risk of death from novel coronavirus disease (COVID-19)', J Clin Med. 2020;9(2). https://doi.org/10.3390/jcm9020580

19. Wax RS, Christian MD. 'Practical recommendations for critical care and anesthesiology teams caring for novel coronavirus (2019-nCoV) patients', Canadian Journal Of Anesthesia-Journal Canadien D Anesthesie. 2020;1-9. https://doi.org/10.1007/s12630-020-01591-x

20. Linton $\mathrm{NM}$, et al. 'Incubation period and other 
epidemiological characteristics of 2019 novel coronavirus infections with right truncation: A statistical analysis of publicly available case data', Journal Of Clinical Medicine. 2020;9(2). https://doi.org/10.3390/jcm9020538

21. Pan Y, et al. 'Potential false-negative nucleic acid testing results for severe acute respiratory syndrome coronavirus 2 from thermal inactivation of samples with low viral loads.', Clinical Chemistry. 2020; England.

22. Haider $\mathrm{N}$, et al. 'Passengers' destinations from China: low risk of novel coronavirus (2019-nCoV) transmission into Africa and South America', Epidemiology and Infection. 2020;148. https://doi.org/10.1017/S0950268820000424

23. Lee A. 'Wuhan novel coronavirus (COVID-19): Why global control is challenging?', Public Health. 2020;179: A1-A2. https://doi.org/10.1016/j.puhe.2020.02.001

24. Wang YXJ, et al. 'The role of CT for Covid-19 patient's management remains poorly defined', Annals of Translational Medicine. 2020;8(4). https://doi. org/10.21037/atm.2020.02.71

25. Anzai A, et al. 'Assessing the impact of reduced travel on exportation dynamics of novel coronavirus infection (COVID-19)', Journal of Clinical Medicine. 2020;9(2). https://doi.org/10.3390/jcm9020601

26. Bwire GM, Paulo LS. 'Coronavirus disease-2019: is fever an adequate screening for the returning travelers?', Tropical Medicine and Health. 2020;48(1). https://doi. org/10.1186/s41182-020-00201-2

27. Rong $X$, et al. 'Effect of delay in diagnosis on the transmission of COVID-19', Mathematical Biosciences and Engineering. 2020;17(3):2725-2740. https://doi. org $/ 10.3934 / m b e .2020149$

28. Gostic K, et al. 'Estimated effectiveness of symptom and risk screening to prevent the spread of COVID-19', Elife. 2020;9. https://doi.org/10.7554/eLife.55570

29. Xiao C. 'A novel approach of consultation on 2019 novel coronavirus (COVID-19)-Related psychological and mental problems: Structured letter therapy', Psychiatry Investigation. 2020;17(2):175-176. https:// doi.org/10.30773/pi.2020.0047

30. Cao J et al. 'Clinical Features and Short-term Outcomes of 102 Patients with coronavirus disease 2019 in Wuhan, China.', Clinical infectious diseases : an official publication of the Infectious Diseases Society of America. 2020; The United States. https://doi.org/10.1093/cid/ciaa243

31. Calda $P$, et al. 'Coronavirus infection and pregnancy (COVID-19) Statement of Czech society for ultrasound in obstetrics and gynecology', Aktualni Gynekologie A Porodnictvi. 2020;12: 17-19.
32. Karimi-Zarchi M, et al. 'Vertical transmission of coronavirus disease 19 (COVID-19) from infected pregnant mothers to neonates: A review.' Fetal Pediatr Pathol, 2020;1-5, England. https://doi.org/10.1080/155 13815.2020.1747120

33. Shang W, et al. 'The outbreak of SARS-CoV-2 pneumonia calls for viral vaccines', NPJ Vaccines. 2020;5(1). https:// doi.org/10.1038/s41541-020-0170-0

34. Xiao $\mathrm{H}$, et al.'The effects of social support on sleep quality of medical staff treating patients with coronavirus disease 2019 (COVID-19) in January and February 2020 in China', Med Sci Monit. 2020;26. DOI: 10.12659/MSM.923921

35. Li G, De Clercq E. 'Therapeutic options for the 2019 novel coronavirus (2019-nCoV)', Nature Reviews Drug Discovery. 2020;19(3):149-150. https://doi.org/10.1038/ d41573-020-00016-0

36. Cao Y-C, Deng Q-X, Dai S-X 'Remdesivir for severe acute respiratory syndrome coronavirus 2 causing COVID-19: An evaluation of the evidence.', Travel Medicine and Infectious Disease. 2020; 101647, Netherlands. https:// doi.org/10.1016/j.tmaid.2020.101647

37. Baruah V, Bose S. 'Immunoinformatics-aided identification of $T$ cell and $B$ cell epitopes in the surface glycoprotein of 2019-nCoV', J Med Virol. 2020;92(5):495-500. https:// doi.org/10.1002/jmv.25698

38. Dong L, Hu S, Gao J. 'Discovering drugs to treat coronavirus disease 2019 (COVID-19)', Drug Discoveries and Therapeutics. 2020;14(1):58-60. https://doi. org/10.5582/ddt.2020.01012

39. MacKenzie D. 'The hunt for COVID-19 drugs. Many drugs and vaccines are now being developed and tested', New Scientist. 2020;245(3273):10. https://doi.org/10.1016/ S0262-4079(20)30525-X

40. Martinez MA. 'Compounds with therapeutic potential against novel respiratory 2019 coronavirus.', Antimicrob Agents Chemother. 2020; United States. doi: 10.1128/ AAC.00399-20. https://doi.org/10.1128/AAC.00399-20

41. Lim J, et al. 'Case of the index patient who caused tertiary transmission of coronavirus disease 2019 in Korea: The Application of Lopinavir/Ritonavir for the treatment of COVID-19. Pneumonia Monitored by Quantitative RT-PCR', J Korean Med Sci. 2020;35(6). https://doi. org/10.3346/jkms.2020.35.e79

42. Spiteri G, et al. 'First cases of coronavirus disease 2019 (COVID-19) in the WHO European Region, 24 January to 21 February 2020', Eurosurveillance. 2020;25(9):2-7. https:// doi.org/10.2807/1560-7917.ES.2020.25.9.2000178 